\title{
A distância (in)correta
}

The (un)correct distance

\author{
Janaina Fontes Leite
}

Janaína Fontes Leite

Doutoranda do Programa de Pós-Graduação em Artes Cênicas da Escola de

Comunicações e Artes da Universidade de São Paulo (USP).

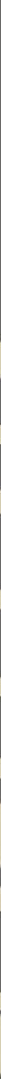




\section{Resumo}

"Ele escreveu uma peça sobre negros" era o título explosivo do projeto inicial do dramaturgo e diretor Alexandre Dal Farra que deu origem à longa jornada do espetáculo que é tema deste texto. Mas diferentemente do que se pode tomar em uma abordagem inicial demasiadamente reativa, o título, intencionalmente, já colocava seu próprio projeto sob suspeita. Quem é esse "ele" que se arroga tal posição? Certamente um "ele" que se distingue de seu "objeto" - esse genérico e autoritário "negros" que termina a frase. De certa forma, sem que tivéssemos a menor ideia de onde o projeto nos levaria, já estávamos no encalço desse "branco" que figuraria no título definitivo do espetáculo que estreou em março de 2017 em São Paulo: Branco: o cheiro do lírio e do formol. Este artigo procura retomar alguns fios do processo relacionando-os à ideia de "distância correta" proposta por Hal Foster em seu texto "O artista como etnógrafo". Palavras-chave: Real, Referente, Abjeção.

\section{Abstract}

"Ele escreveu uma peça sobre negros" was the explosive title of the original project of the playwright and director Alexandre Dal Farra that gave rise to the long journey of the spectacle that is the theme of this text. But unlike what one might take in an overly reactive initial approach, the title intentionally put its own project under suspicion. Who is this "he" who claims such a position? Certainly it is a "he" that distinguishes himself from his "object" - that generic and authoritarian "blacks" that ends the sentence. In a way, without our having any idea where the project would take us, we were already on the trail of this "white" that would appear in the definitive title of the show that premiered in March 2017 in São Paulo: Branco: o cheiro do lírio e do formol. This article tries to return to some threads of the process relating them to the idea of "correct distance" proposed by Hal Foster in his text "The artist as ethnographer."

Keywords: Real, Referent, Abjection.

Como uma das criadoras do espetáculo, hesito entre fazer um relato mais colado à experiência diária do processo, da temporada, das tensões que envolveram o trabalho ou enveredar por um caminho mais analítico. No entanto, não é a isso que o "distância (in)correta" do título do artigo se refere. 
Não foi sem espanto que me deparei com o texto "O artista como etnógrafo", de Hal Foster. Falo do espanto, pois Foster escreve o texto em 1996 e faz diversas alusões a textos da década anterior, já sobre assuntos que parecem, somente agora, mais de vinte, trinta anos depois, eclodirem em solo brasileiro. Espanto, também, porque vejo nesses textos pontos que me ajudam, como artista, a entender os impasses que um projeto como Branco necessariamente iria enfrentar, tanto em sua elaboração como em sua recepção.

Em seu livro O retorno do real, Hal Foster, depois de apontar para o que se converteu em uma espécie de razão cínica nos anos 1980, desenvolve o que seria uma consequência crítica desse momento, dando ensejo para dois movimentos na década seguinte: de um lado, para o que ele chama de "virada para o real," de outro, "virada para o referente." Para ele, ainda que ambas as posições definam diferentes genealogias da arte e da teoria, elas têm em comum a ênfase no corporal e no social, no abjeto e no site-specific. É nesse contexto que Foster vai confrontar duas experiências estéticas muito diversas: aquela que se faz no registro do trauma - ou do "real traumático", como ele diz, mas de forma a trazer em seu bojo seu correlato, que é a abjeção em sua indefinição entre sujeito e objeto -, e aquela que se faz sob a égide do referente e que reivindica sim o trauma, mas para apontar os sujeitos culturais que podem testemunhá-lo, revitalizando a categoria de sujeito para aqueles a quem, historicamente, essa posição foi negada.

Essa segunda vertente vai marcar profundamente a migração da concepção de um sujeito definido em termos de posição econômica para um sujeito definido em termos de identidade cultural. É essa mudança significativa que está na base de novos eixos importantes que vão balizar não só a produção em arte, mas a história, a sociologia e a antropologia, que passam a se deparar com o problema da "distância correta", mencionado acima.

"A codificação automática da diferença aparente como identidade manifesta e da condição de outro [otherness] como exterioridade [outsideness] tem de ser posta em questão. Pois esse código poderia não só reduzir a identidade à sua essência, como também restringir a identificação, tão importante para a filiação cultural e a aliança política (a identificação nem sempre é mecenato ideológico)" (FOSTER, 2014, p. 163). 
Em se tratando de arte - mas não só - o problema da "distância correta" vem impondo uma série de questões desde que a arte, a partir dos anos 1970, deixou as galerias e museus para integrar um circuito mais amplo da cultura, atravessada por diferentes discursos e diretamente implicada em debates ineditamente promovidos pelos movimentos sociais. O sujeito não é mais o sujeito fenomenológico das teorias da recepção, mas um sujeito social "definido na linguagem e marcado pela diferença (econômica, étnica, sexual etc.)" (Ibid., p. 174).

Como enfrentar tais questões sem recair na ideia limitante da "representação como um deslocamento literal"? Foster sublinha esse limite e o tabu gerado a partir da "indignidade de falar por outros" que foi o calcanhar de Aquiles disseminado pela esquerda cultural nos anos 1980 nos EUA, e que resultou lá, segundo Foster, tanto em "silêncio crítico" quanto na ausência de discursos alternativos que pudessem propor caminhos para isso que ele diz ser o "enigma do sujeito", pois a questão da "distância correta" abarca as relações do sujeito com "sua própria imagem corporal, seus outros culturais e suas próteses tecnológicas" (Ibid., p. 207).

O autor cita então alguns eventos dos anos 1980, como a audiência de Clarence Thomas, o caso Rodney King e o julgamento de Simpson, que suscitaram violentas emoções e embates fortemente divididos em torno de questões raciais, sexuais e sociais.

Não à toa, ainda sobre a questão da distância correta, o autor vai falar da "paranoia" como um fenômeno que tomou tanto a direita quanto a esquerda, pois que a paranoia, justamente, deflagra uma "confusão entre distância e proximidade interior e exterior". E tem em comum, para a esquerda e para a direita, apresentar-se como "último refúgio do sujeito ameaçado pela alteridade" (Ibid., p. 207).

Retomando o fio com a criação do espetáculo em questão, sobre o primeiro texto escrito, se em um algum momento achamos que a peça seria feita por atores negros e brancos, entendemos cada vez mais que os "negros" de que se tratava no material não eram negros e negras reais, nunca foram, mas sim uma espécie de alucinação projetiva, assumidamente parcial. Nessa etapa, assumimos, portanto, que se tratava disso que Foster chama de "obra 
paraláctica", que procura "enquadrar o enquadrador enquanto este enquadra o outro" (Ibid., p. 185).

Amigo, será que daria para trazer a conta aqui para nós? CARALHO NÃO ACREDITO QUE EU ESTOU DE NOVO AQUI FAZENDO ISSO, REFORÇANDO AS PORRAS DOS ESTEREÓTIPOS, FALANDO COM A PORRA DO GARÇOM NESSA PEÇA ULTRA RACISTA SOBRE O RACISMO, VAI TOMAR NO CU CARALHO!!!! Chamando o garçom de "amigo", o garçom que obviamente, dentro da minha cabeça escrota, é negro! "Amigo! Amigo, será que daria pra trazer a conta?" Eu chamo você de amigo, mesmo, não como um tipo de costume involuntário, inconsciente, mas de forma INTENCIONAL, COM VONTADE DE ME APROXIMAR MESMO, EU USO ESSA PALAVRA, CHEIA DE AMOR POR ELA, QUERENDO AQUI ALTERAR UM POUCO DA LÓGICA QUE REGE ESSE LUGAR, QUE REGE AS NOSSAS VIDAS, A ALTERAÇÃO DA VIDA COMEÇA COM PEQUENAS COISAS, É ISSO QUE EU ESTOU FAZENDO, TE CHAMANDO DE AMIGO EXATAMENTE DESSA FORMA, quer dizer, como quem venera esse tipo de expressão e vê por trás dela toda uma intenção de aproximação real, como quem se nega a aderir à ideologia objetificante da diferença, como quem quer realmente o contato social, o contato amigável, o amor. (DAL FARRA, 2016)

No entanto, entre o real e o fantasmático, o jogo de representação era refém também da "paranoia" de que fala Foster, revelando a sua "incapacidade de imaginar" o outro. E essas são palavras de um dos provocadores convidados durante o processo, José Fernando Azevedo, que foram determinantes para que não abortássemos o projeto de montar essa primeira versão.

Até aqui, estávamos tentando dois movimentos: primeiro, nos distanciar do modelo que marcou o artista etnógrafo nos anos 1980, que era o do "mecenato ideológico" que, em sua ânsia de se identificar com o outro, não fazia mais do que marcar sua "autoridade etnográfica" e sua "condescendência sociológica". E, segundo, assumir essa fantasmagoria projetiva de forma a satirizar o próprio branco em seus limitados mecanismos de representação do outro. Mais ainda, que em uma dimensão crítica, a própria estrutura do trabalho com posições exageradamente demarcadas, pelo seu excesso de consciência e pretensão racionalista, que trabalhava exaustivamente no intuito de flagrar todos os passos em falso do homem branco, era ainda uma peça 
demasiadamente afirmativa, pois se atinha ao que já sabíamos sobre nós, brancos.

Uma segunda versão, inteiramente nova, foi escrita, mas tentando corrigir a primeira. Era dessa maneira que ela era descrita na versão final do trabalho, que estreou carregando os ecos do seu turbulento processo:

Escrevi uma peça nova, sentindo o tempo todo que dessa vez eu estava me colocando de forma responsável. Essa nova peça falava sobre uma jornada de aprendizagem de um sobrinho com o seu tio, que o levava para conhecer o sítio que tinha sido do seu avô, e lá acontecia uma série de coisas, até que o tio se embriagava e o sobrinho tinha que voltar guiando para casa. Nesse retorno, ele atropelava uma mulher negra. Eles acabavam levando a mulher, desacordada, para a casa do sítio, e depois descobriam que ela fazia parte de um tipo de movimento que, ao dar falta dela, ia à sua procura, encontrava o tio e o sobrinho, e os matavam. Achei que eu tinha conseguido dar conta do problema. Eu explicitava a minha posição: eu era contra o racismo, eu era estruturalmente contra os brancos, contra mim mesmo, e a peça procurava esmiuçar a forma como o racismo aparecia, de maneiras diferentes, mas aparecia nos dois brancos: tanto no tio (um pequeno proprietário brasileiro típico), quanto no sobrinho, um rapaz muito incomodado com essas questões, mais "humanista" etc. O tal sobrinho se via de repente capturado por uma situação que o igualava materialmente ao seu tio, e o seu discurso "humanista" se mostrava inócuo, irrelevante e patético. (DAL FARRA, 2016)

Concluímos que essa era uma solução fácil. Um deus ex machina para um processo que foi aumentando suas condições de temperatura e pressão. Uma vontade de apaziguar, imediatamente, conflitos que permaneciam em aberto. "Morrer" dentro daquela ficção, se posicionar do lado certo da história - ou seja, do lado da legítima justiça reparadora dos negros e negras - era uma saída realmente fácil, mas que não tocava as nossas próprias contradições.

Gostaria agora de falar um pouco mais da terceira via que resultou no espetáculo estreado. 


\section{Nem sujeito nem objeto}

"Enquadrar-se enquadrando o outro" pode ser uma possível saída diante do impasse do excesso de identificação que apagaria as marcas das diferentes posições ocupadas pelos sujeitos sociais ou da distância excessiva que beira a "desidentificação assassina" (FOSTER, 2014, p. 186). Mas ainda não basta, já que esse mecanismo pode também redundar em uma espécie de sacada de etnógrafo que tomaria essa autorreflexividade como salvaguarda para enveredar por um narcisismo em que, novamente, o outro é apagado e o eu acentuado.

Não é sem risco que Branco enfrentou o problema e buscou, para isso, descentrar o sujeito emissor do discurso. Esse "branco" que toma a palavra não é, portanto, o branco etnógrafo. Nem é o branco sujeito dos discursos da branquidade, crítico consciente de sua posição privilegiada e predisposto a marcar também o seu lugar, se autorracializar, abandonar o lugar "neutro" que ele mesmo se deu na história. Por mais que partilhemos o discurso crítico sobre a branquidade e reconheçamos a urgência das pessoas brancas perceberem sua posição em uma estrutura barbaramente racista como a brasileira, o projeto estético de Branco não se faz nesse terreno assertivo, afirmativo da crítica e da denúncia.

O que entendo cada vez mais é que o espetáculo se deu sob a marca da abjeção. O movimento proposto pelo trabalho estaria, portanto, mais próximo - retomando os dois grandes movimentos de que fala Foster - do "real" do que do "referente". Mais perto do abjeto do que do objeto, para tornar a oposição explícita. A abjeção aqui é tomada em sua dimensão de "crise narcísica", como definiu sua mais importante pensadora, Julia Kristeva. Território ameaçador, terrificante, onde o sujeito ameaça se dissolver. Nem sujeito nem objeto, o abjeto habita uma zona fronteiriça de indefinição, de perdas de certeza, onde o sujeito é ameaçado pelo seu próprio interior. Não à toa, a pele, os orifícios, fazem metáfora para esse estado de passagem em que o sujeito ameaça abjetar-se.

No primeiro ensaio de Branco propus um exercício em que os três atores se sentavam frontalmente, como que em uma mesa de palestra, cada qual com uma garrafa de um litro e meio de água, um copo e o texto da peça. 
O enunciado pedia que os três palestrantes bebessem inteiramente a água da garrafa e só então poderiam começar a dizer o texto. Nunca tínhamos feito esse exercício e não prevíamos o tamanho da dificuldade e do mal-estar que geraria. Terminamos todos vomitando no chão, várias vezes, sem interromper a dinâmica, até que, finalmente, cerca de 40 minutos depois, as garrafas se esvaziaram e começamos a ler uma das cenas, intitulada "Conversa com meus primos brancos":

MEU PRIMO - Eu estava chegando em casa de noite. Tinha um cara estranho lá. Dei uma volta no quarteirão com o carro. Liguei para o segurança da rua. Fiquei esperando na esquina com o farol desligado. $O$ segurança chegou, deu uns gritos, e o cara respondeu umas coisas, mas o segurança mostrou para ele a arma, e aí o cara foi embora na mesma hora. Eles se entendem muito bem entre si. Sabem como lidar uns com os outros. Os bandidos e os seguranças. São dois lados da mesma moeda!

EU - Por que você contou essa porra dessa história agora?? O que esse cara aí estava fazendo? Você tipo julgou ele do nada?

MEU PRIMO - Como assim? O cara era suspeito. Estava lá rodeando a casa, e tudo o mais. Eu estou falando de como acontece a comunicação com esse tipo de gente. É uma questão de linguagem que eu estou querendo abordar...

EU - Mas o cara não era suspeito, talvez!! Pode ser que ele só estivesse tipo andando pela rua, sei lá, lembrando da infância, pensando em outras coisas!!!

MEU PRIMO - O cara saiu correndo por que então? Quem não deve não teme.

MEU IRMÃO - Você fica questionando a parte menos importante da história! É uma história sobre linguagens, sobre comunicação...

EU - Esse cara aí pode ser que estivesse ali quieto, pensando no que fazer, em dúvida... E aí de repente ele é enquadrado de forma escrota!... Imagina, você está andando na rua, pensando na vida, de repente chega um cara de moto e começa a gritar com você, a te ameaçar com uma arma e o caralho? Você faz o que? Fica por ali??

MEU PRIMO - Você está pirando.

MEU IRMÃO - Total. Esse não era o assunto!

EU - Você só achou o cara "suspeito" porque ele era tipo "diferente" de você. A gente sempre suspeita do diferente. Nunca do igual. Mas nós é que somos os grandes suspeitos nessa merda!! A gente é que está sob suspeita! Eu suspeito de mim mesmo o tempo inteiro! A qualquer momento eu posso ter uma recaída e me transformar de repente em um escroto filho da puta como vocês! Se eu não prestar atenção isso pode 
mesmo acontecer, muito rápido!! Que nem outro dia, quando eu parei em um farol, e vi uma família descendo de um carro grande, na frente de um restaurante, descendo de uma Range Rover, ou algo do tipo. Um pai, uma mãe e dois filhos. Eles eram negros. Tinham dois filhos pequenos, dois bebês mesmo, que estavam deitados em um carrinho especial, duplo. O casal estava muito bem vestido. Aquela família de negros estava entrando em uma pizzaria chique, em Higienópolis. Eu vi aquela cena e fiquei naturalmente feliz. Eu me senti leve, senti que o mundo estava melhorando, me senti bem, mesmo. Mas em seguida, quando abriu o farol e eu segui com o meu carro, eu pensei: eu não deveria ter nem notado essa família. O certo seria nem notar. O certo seria eu não ter ficado feliz com aquela cena! Isso era um puta de um racismo escroto, porque era do tipo, "nossa, eles são negros e estão bem vestidos"; mesmo que eu estivesse torcendo a favor deles, isso tinha um pressuposto de desigualdade, mas essa desigualdade estrutura a própria realidade, eu pensei, tentando perdoar a mim mesmo, eu tinha ficado muito feliz com aquilo, eu não era racista, eu era um entusiasta dos negros, eu fico feliz quando eu vejo negros ricos, de classe média... E aí, em seguida, eu pensei que também essa minha alegria, essa minha leveza, essa sensação de que o mundo está melhorando, esse pequeno prazer, decorria de um tipo de culpa que eu já tinha antes, e aquela família tinha sido utilizada por mim para me livrar disso, ela se transformou, para mim, em um tipo de álibi para que eu não precisasse sentir o peso dos meus privilégios, eu a transformei em um argumento de que muitas vezes no futuro eu poderia me utilizar: "Também existem negros bem-sucedidos", e assim por diante! Era um perigo. De novo, era essa sensação, de que a qualquer momento eu poderia me transformar em um cara escroto. O suspeito não era o cara que estava rondando a sua casa, o suspeito era você, que estava olhando o cara rondar a sua casa!!! Você estava correndo todos os riscos de tomar uma atitude opressora, e aí, como você é um branco heterossexual que não dá a mínima para esse tipo de questão, você foi lá e fez exatamente isso, tachou o cara, mandou o outro escorraçar ele! Mas se você tivesse esse medo constante de pensar, sentir e dizer qualquer coisa que pudesse ser lida como algum tipo de pequena ofensa ao outro, você teria tomado muito mais cuidado, e assim, você não teria potencialmente ofendido uma pessoa que não era aquilo que você imaginava, que estava ali rondando a casa de forma desinteressada e o caralho!! Nós, brancos, heterossexuais, homens de classe média, precisamos tomar o cuidado máximo com o que nós dizemos porque tudo o que nós dizemos na verdade, simplesmente por ser dito por nós, se configura como um tipo de ofensa, como um discurso de dominação, essa é a verdade! Então é melhor a gente simplesmente ficar quieto e não dizer mais nada, sobre assunto nenhum, quanto mais 
em relação a esse tipo de problema que claramente não é nosso, como racismo, homofobia, machismo etc. (DAL FARRA, 2016)

O mal-estar físico que se instaurou ali, somado às questões de um texto como este, foi uma justa expressão das dificuldades que já enfrentávamos até ali e, mais ainda, um prenúncio do que se seguiria com a temporada. $A$ cena do vômito não figurou no espetáculo, mas tempos depois permanecia em imagem e sensação em um texto como o que se segue:

Eu fui lá na reunião do bairro. Eles estavam querendo fechar a rua. Eu falei que não. Que não podia. Um outro cara disse que não podia mesmo. Que era um absurdo, que nem precisava tanto assim também. Ele disse que o bairro estava melhorando de qualquer jeito. Quando eu ouvi a palavra "melhorando", eu senti um pouco de enjoo. Mas aí um outro cara falou que agora ia piorar de novo. Que não tinha mais como melhorar. E todo o mundo começou a discutir isso, se ia piorar ou não, coisas assim. Eu fiquei quieto, e fiquei olhando, e todo o mundo estava dando opiniões. Todas as pessoas do bairro. Os vizinhos. E aí eu vi que tinha uma coisa talvez que estava acontecendo em volta das opiniões, em outro lugar, ou até ali mesmo também. $E$ eu fiquei querendo pensar nessa outra coisa, que estava em outro lugar. E ficar lá. No outro lugar. Não ali. Pensei em ir embora dali, porque ali eu me sentia mal, ir embora ia ser melhor para mim, e eu estava pensando nisso tudo, nessas opções, tudo isso eu estava fazendo exatamente ali, naquela reunião de bairro, enquanto eles continuavam discutindo o fechamento da rua. E aí eu me senti meio mal, e eu vomitei um pouco sem querer, ali no chão mesmo, algumas pessoas viram, umas três, mas elas não comentaram e eu tentei disfarçar. Depois eu fiquei pensando nisso também. No fato de que eu tentei disfarçar o vômito. E aí eu resolvi me orgulhar do meu vômito, e disse isso para as pessoas, eu pedi a palavra, e falei que eu tinha acabado de vomitar, e alguns me parabenizaram por isso, e disseram que isso era importante, e disseram até que não iam fechar a rua no fim das contas por causa do meu vômito, coisas assim. E aí eu me senti bem. Mas depois, de noite, eu acordei no meio da noite, com a imagem daquela reunião pulsando na cabeça, como se eu pudesse olhar de fora aquilo tudo, e o meu vômito tinha justamente me jogado para dentro da própria reunião, eu tinha me transformado de novo em uma daquelas pessoas conversando sobre aquilo, sobre a melhor solução em relação à questão de fechar ou não a rua. Vomitei de novo, no meio da noite, no banheiro, e depois, dormi mal o resto da noite, e acordei me sentindo mal de novo, e continuei assim até agora, vomitando de vez em quando sem querer. Isso faz uns oito meses, ou um ano ou mais, que toda noite eu vomito 
assim. Eu nunca falei sobre isso porque eu tinha medo que o meu vômito se transformasse novamente nisso, em um argumento adorável e bonito. Então, eu resolvi só ficar vomitando, mesmo, sem falar nada sobre isso, sem deixar que o meu vômito gerasse nada, a não ser mal-estar - em mim e talvez nos outros também, que estão em volta de mim nesse tipo de lugar. (DAL FARRA, 2017)

O vômito aqui materializa, além do mal-estar, esse trânsito entre dentro e fora que marca a experiência do espetáculo. Nesse sentido, a pele, no caso a pele branca, foi explorada ostensivamente na encenação, onde abundava sua exposição através das escassas peças de figurino que os atores vestiam, sendo ressaltada em uma espécie de viscosidade, pois que elas eram gradualmente besuntadas de todo tipo de pasta, creme, pós, até o seu ápice, quando os atores abjetavam sua própria cara criando máscaras brancas grotescas que os colavam a figuras de senhores de engenho. Uso "abjetar", justamente, pois em nenhum momento deixamos de identificar os senhores de engenho que também somos nós.

O branco não era analisado, pensado como objeto de um discurso racional, razoável, mas era desentranhado, e essa era talvez a causa do mal-estar partilhado pela plateia branca, conforme nos foi diversas vezes relatado.

Ainda que a culpa possa ser uma face desse processo - e nem penso que uma face inválida, já que a culpa é um dos principais elementos do amor e da reparação, se pensarmos em termos psicanalíticos -, a experiência se dava mais ainda pelo desrecalque de uma estrutura que nos forma e nos deforma, a todos nós, brancos.

Sem dúvida não é um movimento evidente e os riscos não são poucos. Abandonamos o projeto inicial, talvez impossível hoje, de uma "distância correta" desse "outro", o negro, e nos fizemos material de choque, eliminando, portanto, distâncias, e propondo abjetar o branco em nós. Foi o passo in-correto que pudemos dar nesse momento.

A escravidão e a estrutura racista que herdamos são a base do que provavelmente é o maior trauma da sociedade brasileira e, como todo trauma profundo, a violência do seu recalque e a dimensão de seu tabu não são facilmente contornáveis. 
Tudo o que se deu em torno da peça, para além dela inclusive, me parece ser, exclusivamente, da ordem do sinthoma.

\section{Referências bibliográficas}

DAL FARRA, A. Passeio por propriedades. 2016.

. Branco: o cheiro do lírio e do formol. 2017.

FOSTER, H. O retorno do real: a vanguarda no final do século XX. São Paulo: Cosac Naify, 2014.

Recebido em 18/10/2017

Aprovado em 23/10/2017

Publicado em 26/12/2017 